Supporting Information

\title{
Thienopyrrolo[3,2,1-jk]carbazoles: Building Blocks for Functional Organic Materials.
}

\author{
Dorian Bader, Johannes Fröhlich, Paul Kautny* \\ Institute of Applied Synthetic Chemistry, TU Wien, Getreidemarkt 9/163, A-1060 Vienna, Austria \\ *paul.kautny@tuwien.ac.at
}

Table of Contents

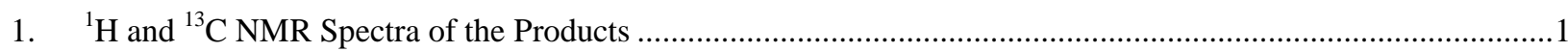

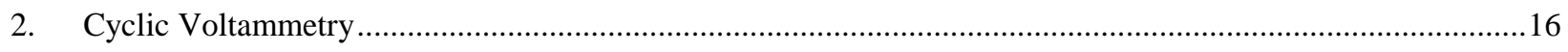

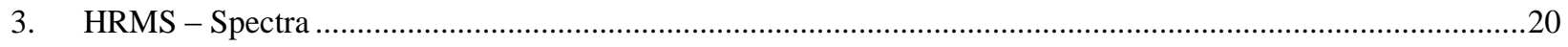

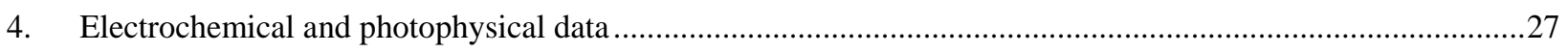

1. ${ }^{1} \mathrm{H}$ and ${ }^{13} \mathrm{C}$ NMR Spectra of the Products 


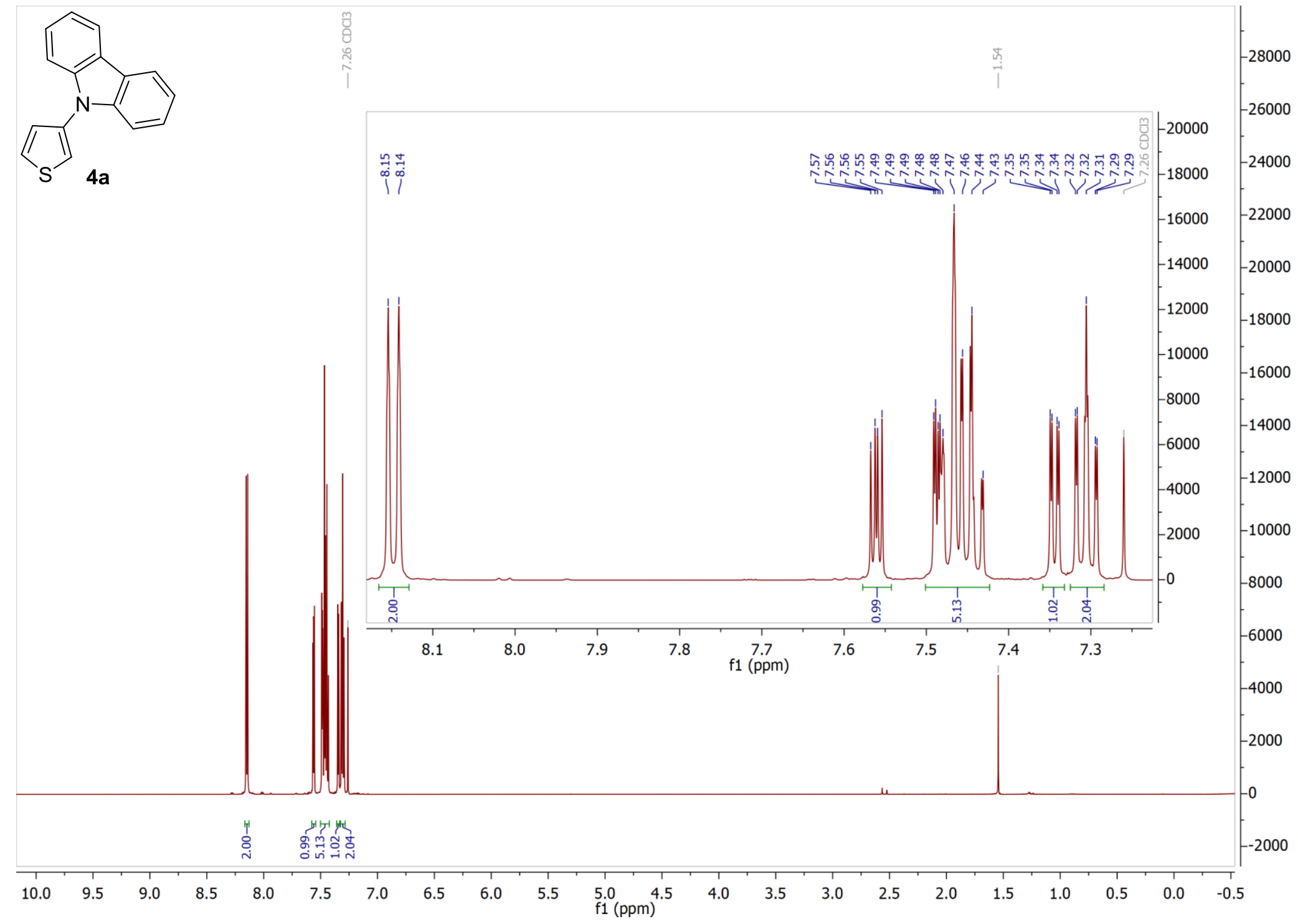

Figure $S 1:{ }^{1} H$ NMR spectrum of $4 a$ 


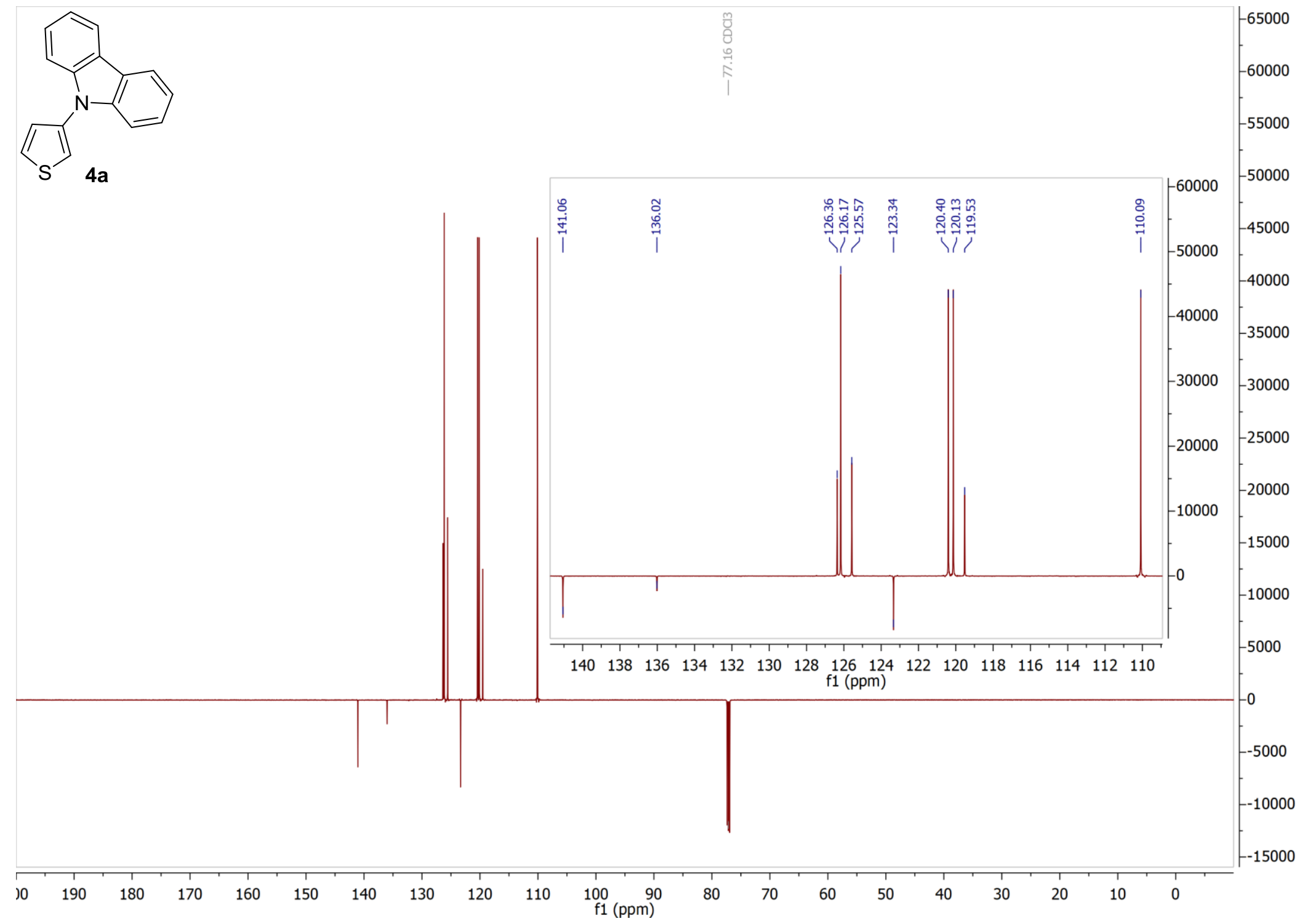

Figure S $2:{ }^{13} \mathrm{C} N M R$ spectrum of $4 a$ 


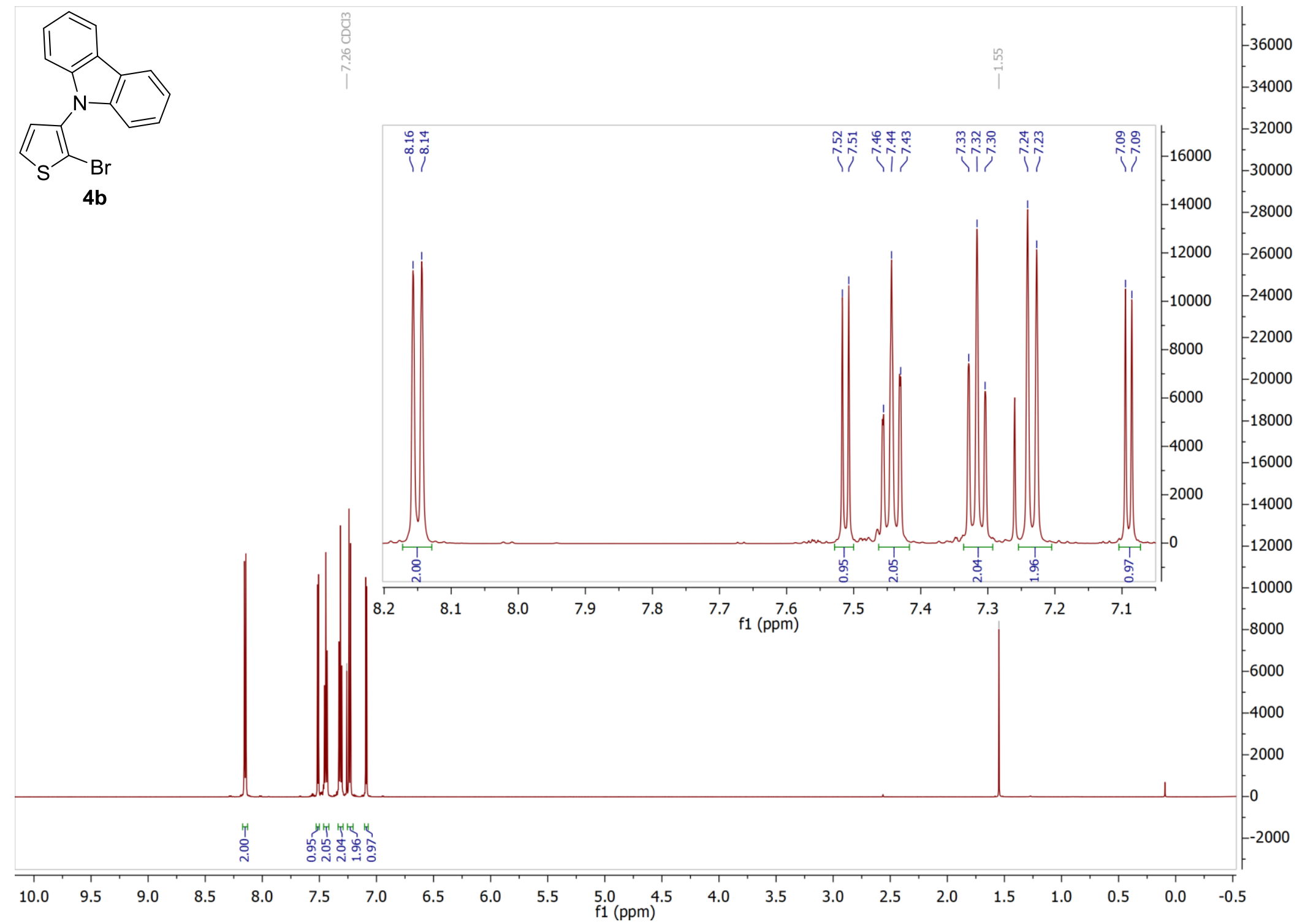

Figure $\mathbf{S} 3:{ }^{1} \mathrm{H}$ NMR spectrum of $\mathbf{4 b}$ 


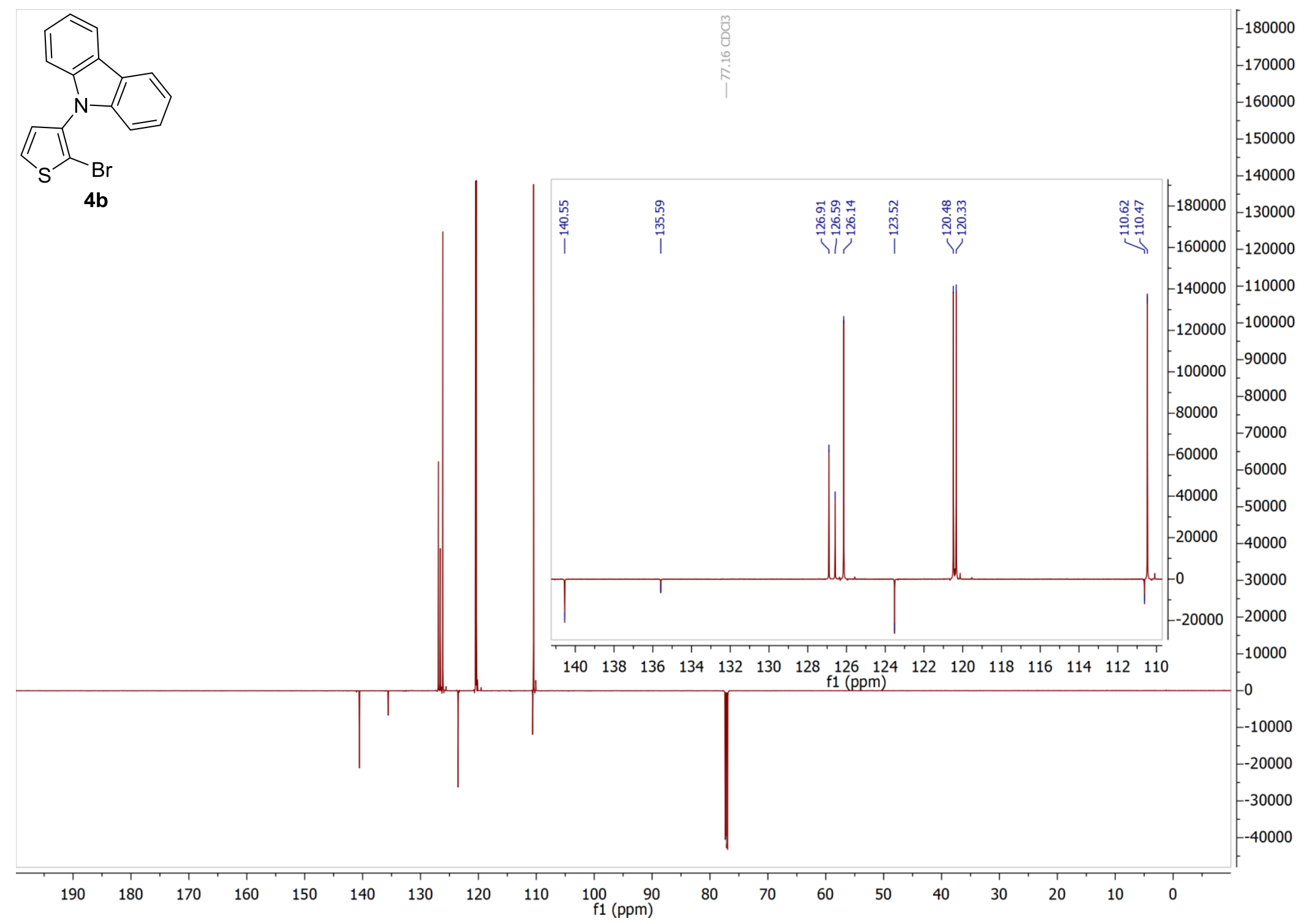

Figure $S 4:{ }^{13} \mathrm{C} N M R$ spectrum of $4 \mathbf{b}$ 


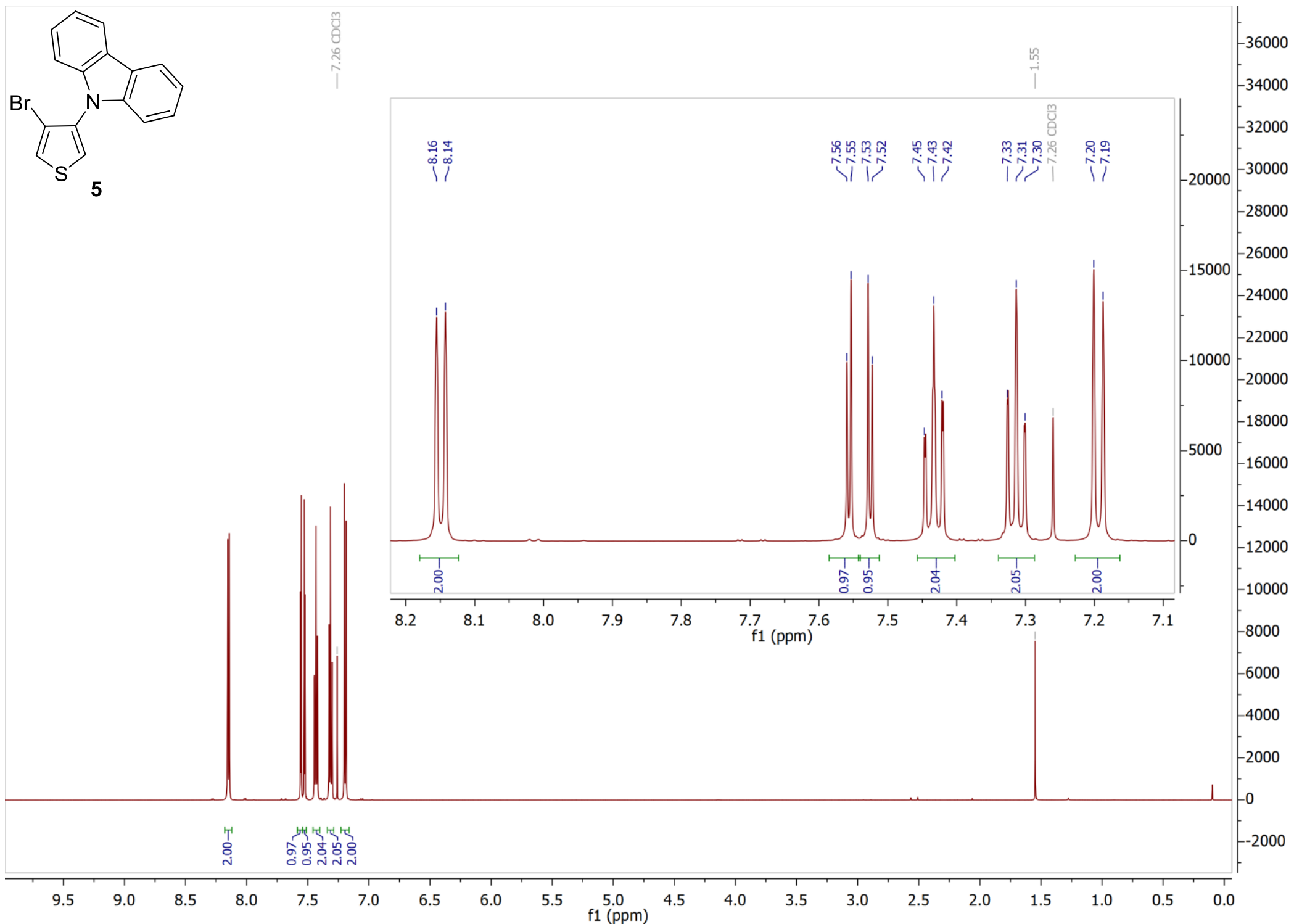

Figure $\mathbf{S} 5:{ }^{1} \mathrm{H}$ NMR spectrum of 5 


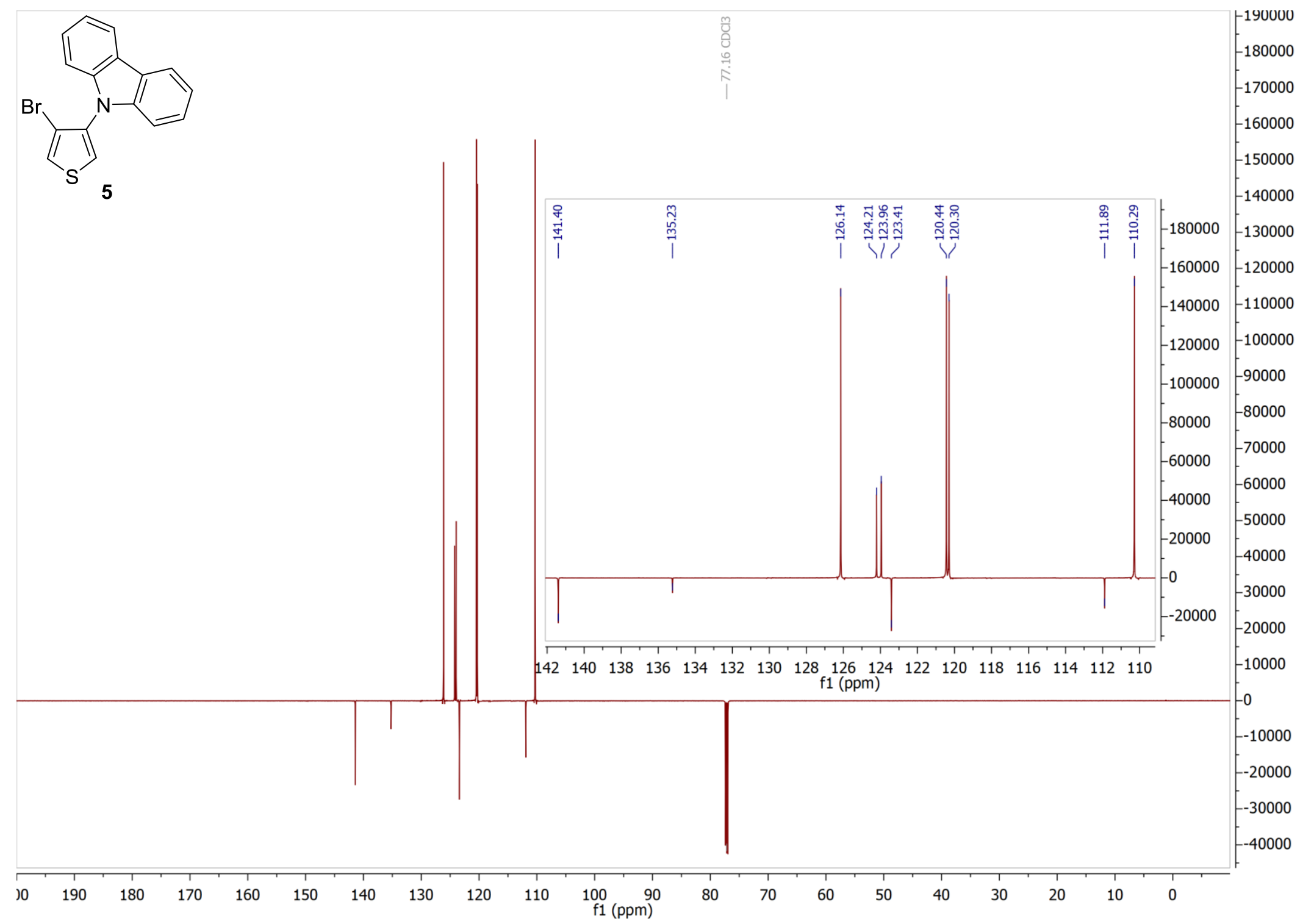

Figure S 6: ${ }^{13} \mathrm{C}$ NMR spectrum of 5 


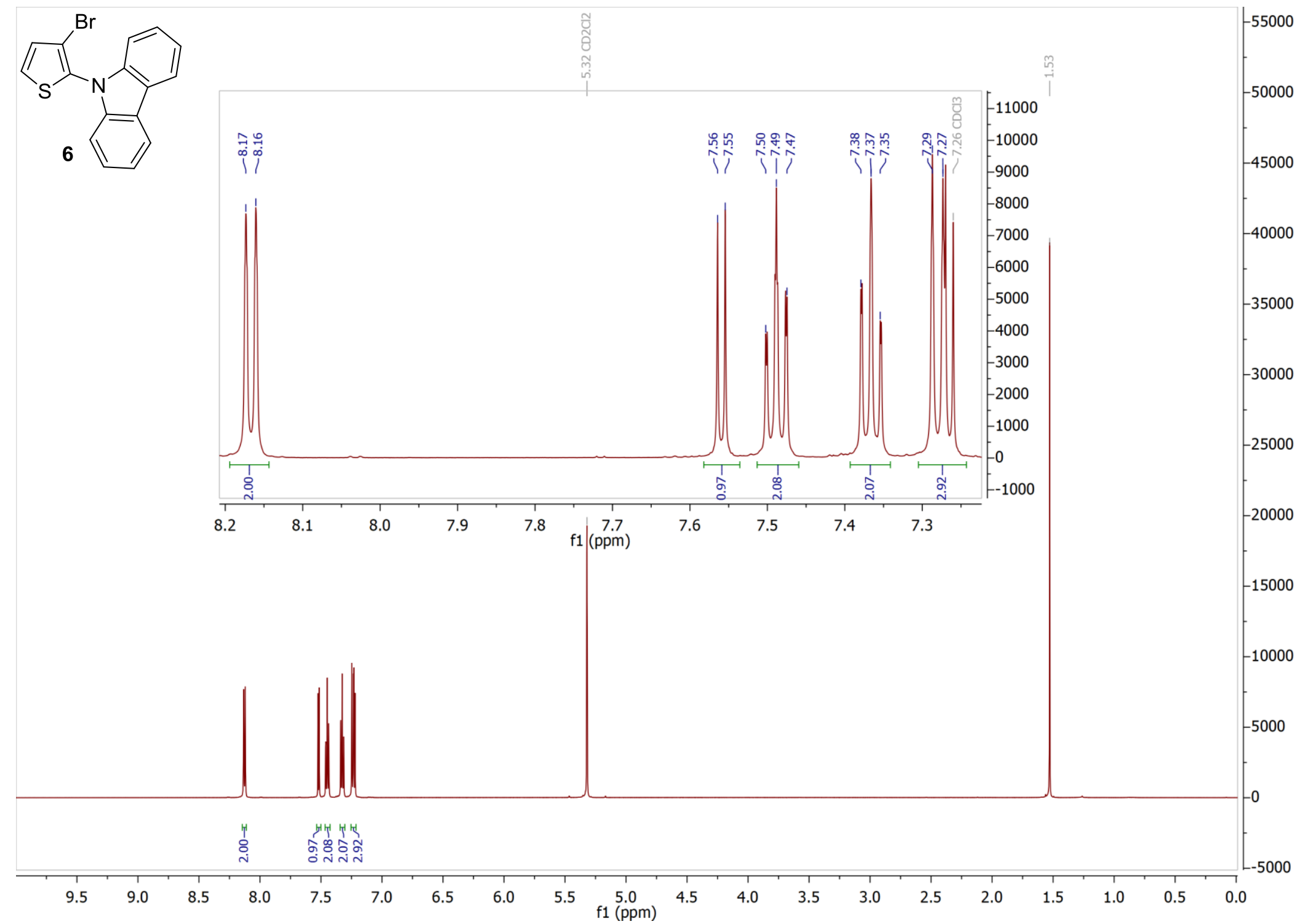

Figure S 7: ${ }^{1} \mathrm{H}$ NMR spectrum of 6 


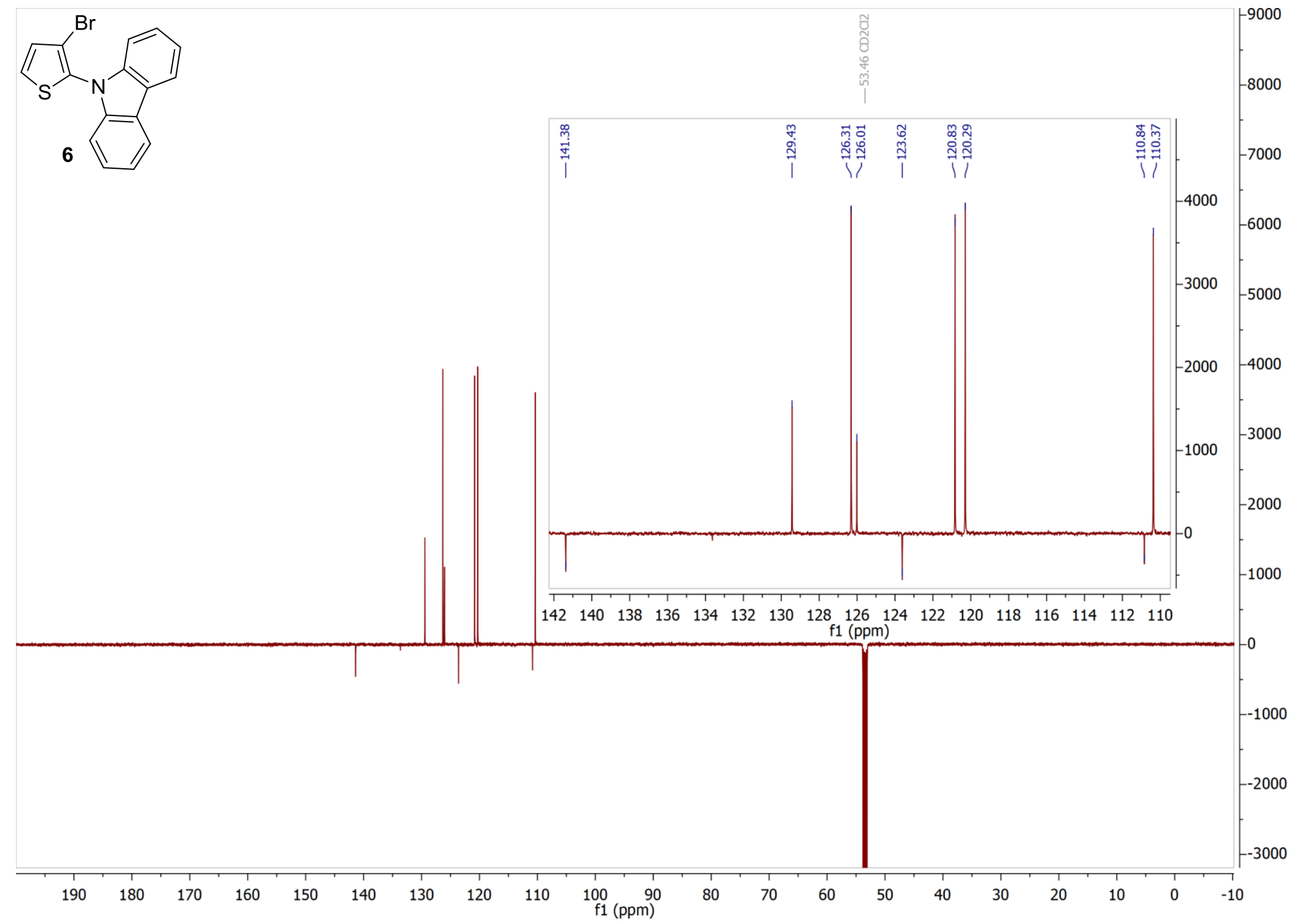

Figure S 8: ${ }^{13} \mathrm{C}$ NMR spectrum of 6 


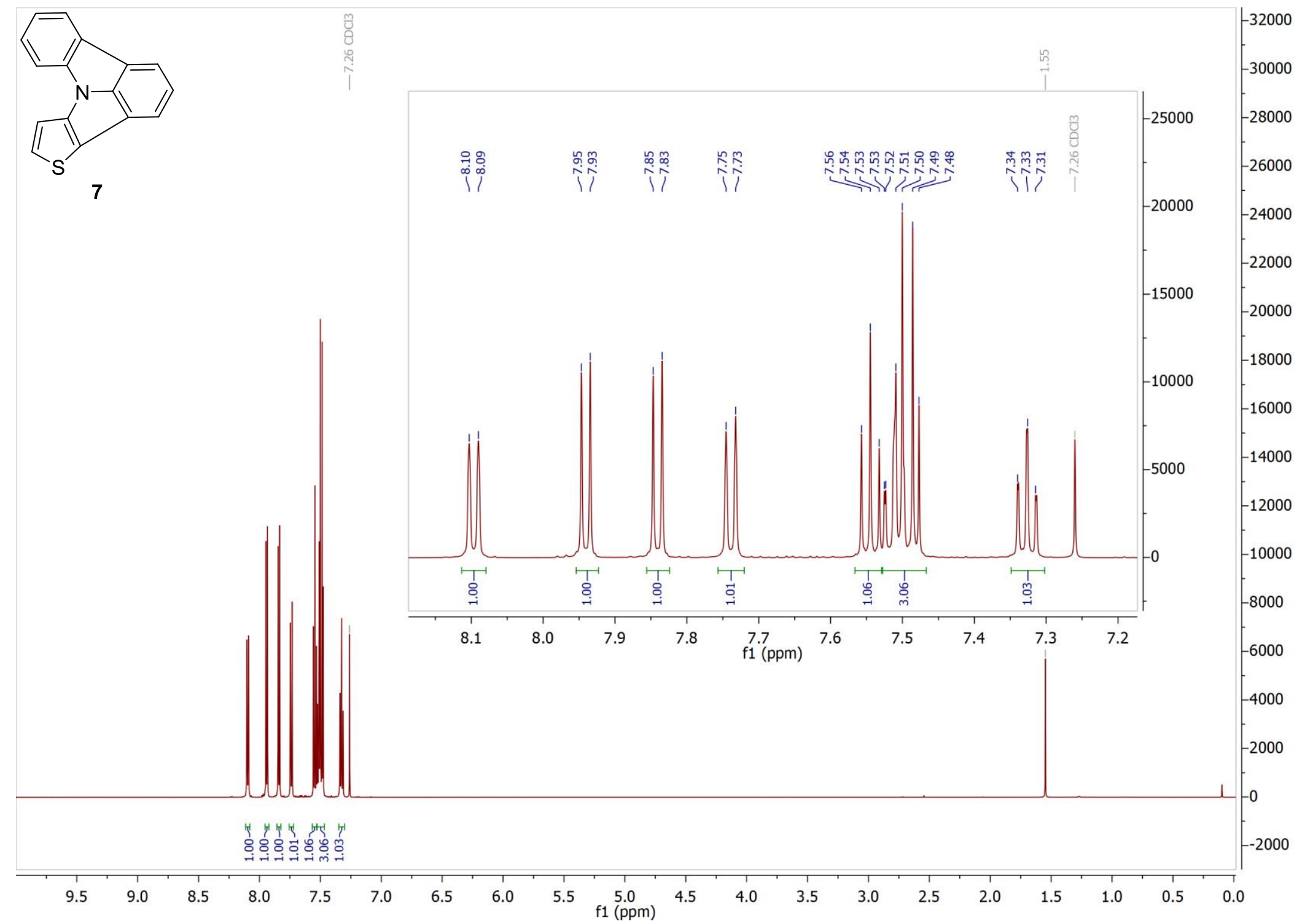

Figure $\mathbf{S} 9:{ }^{1} \mathrm{H}$ NMR spectrum of 7 


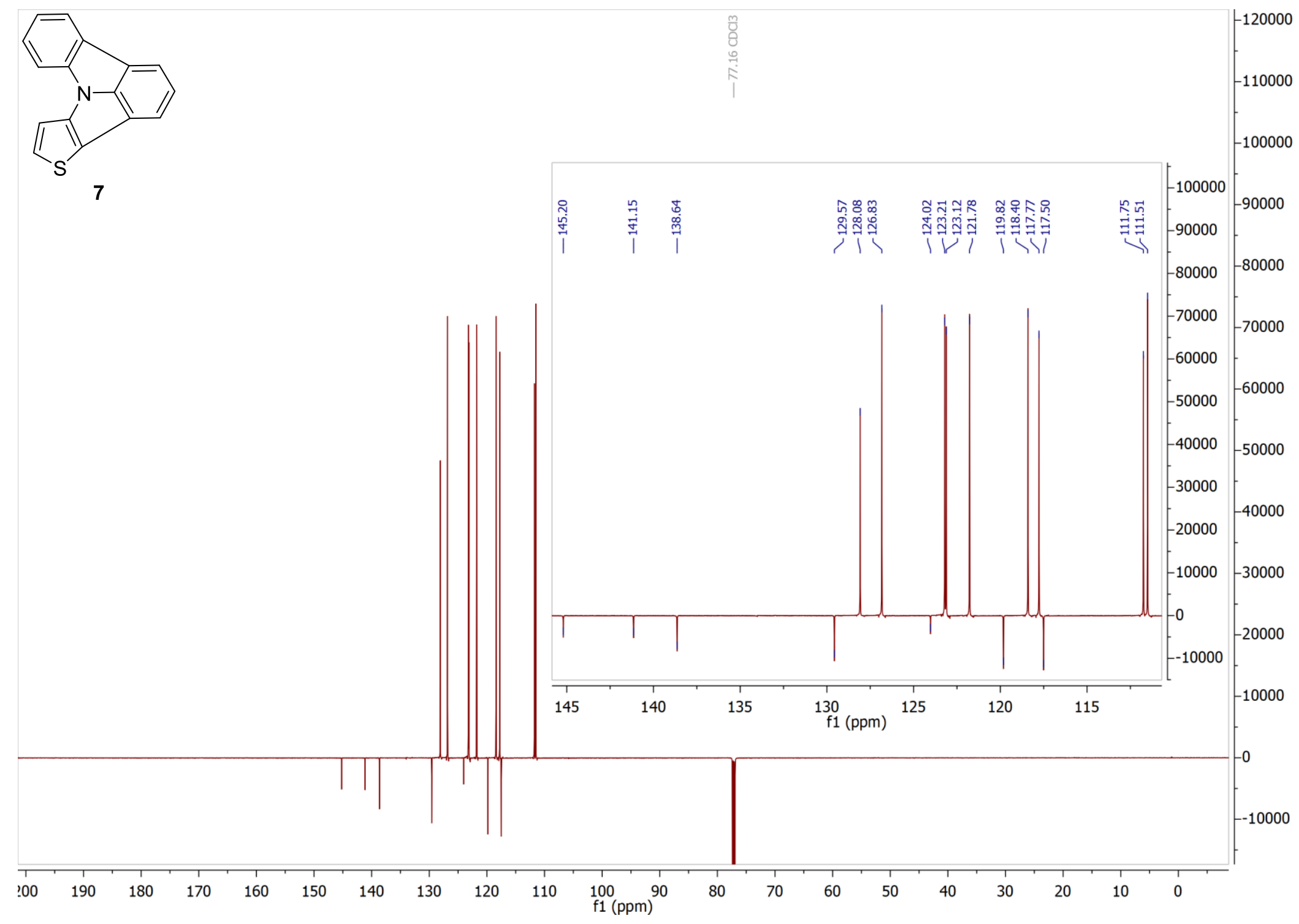

Figure S 10: ${ }^{13} \mathrm{C}$ NMR spectrum of 7 


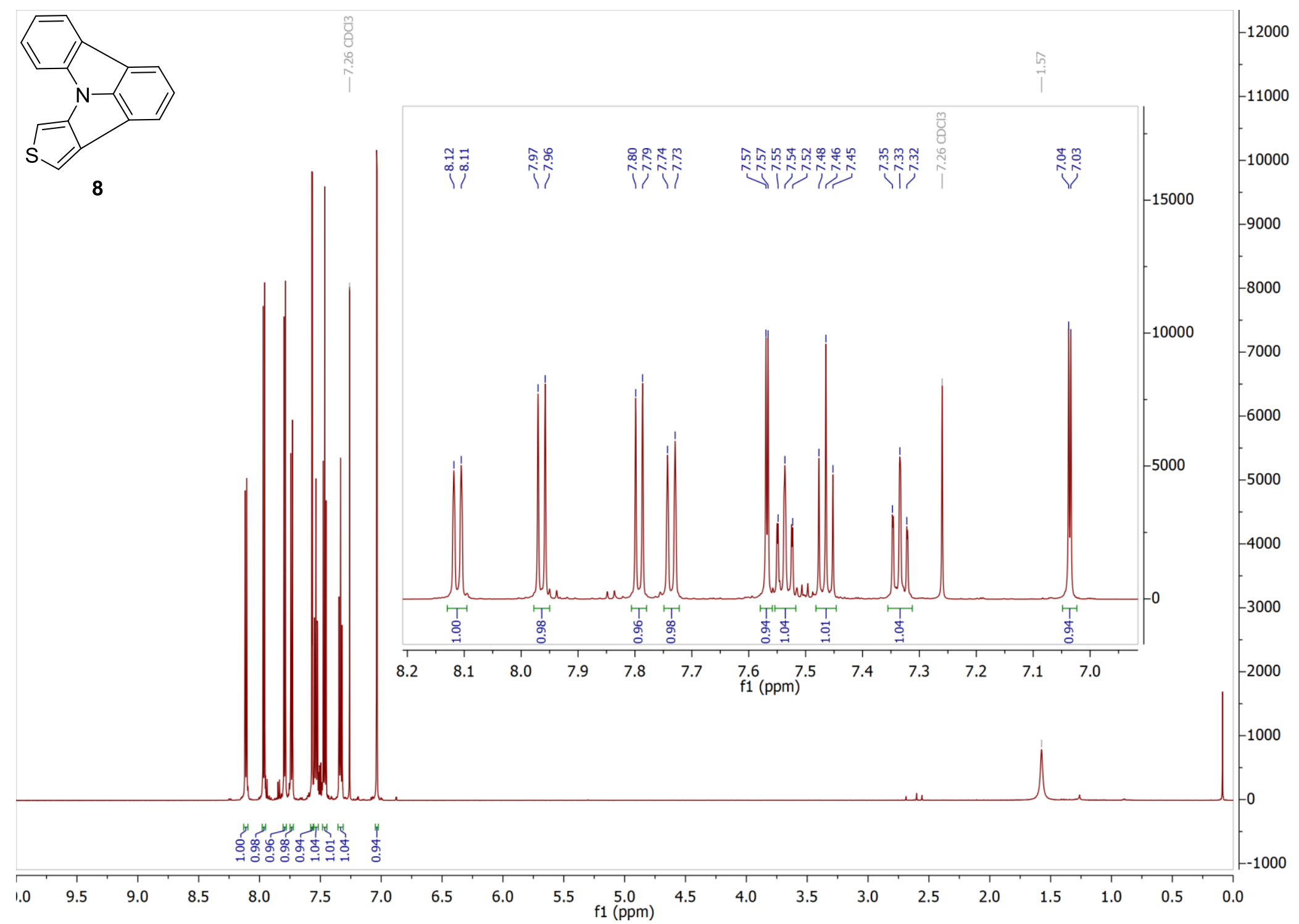

Figure S 11: ${ }^{1}$ H NMR spectrum of 8 


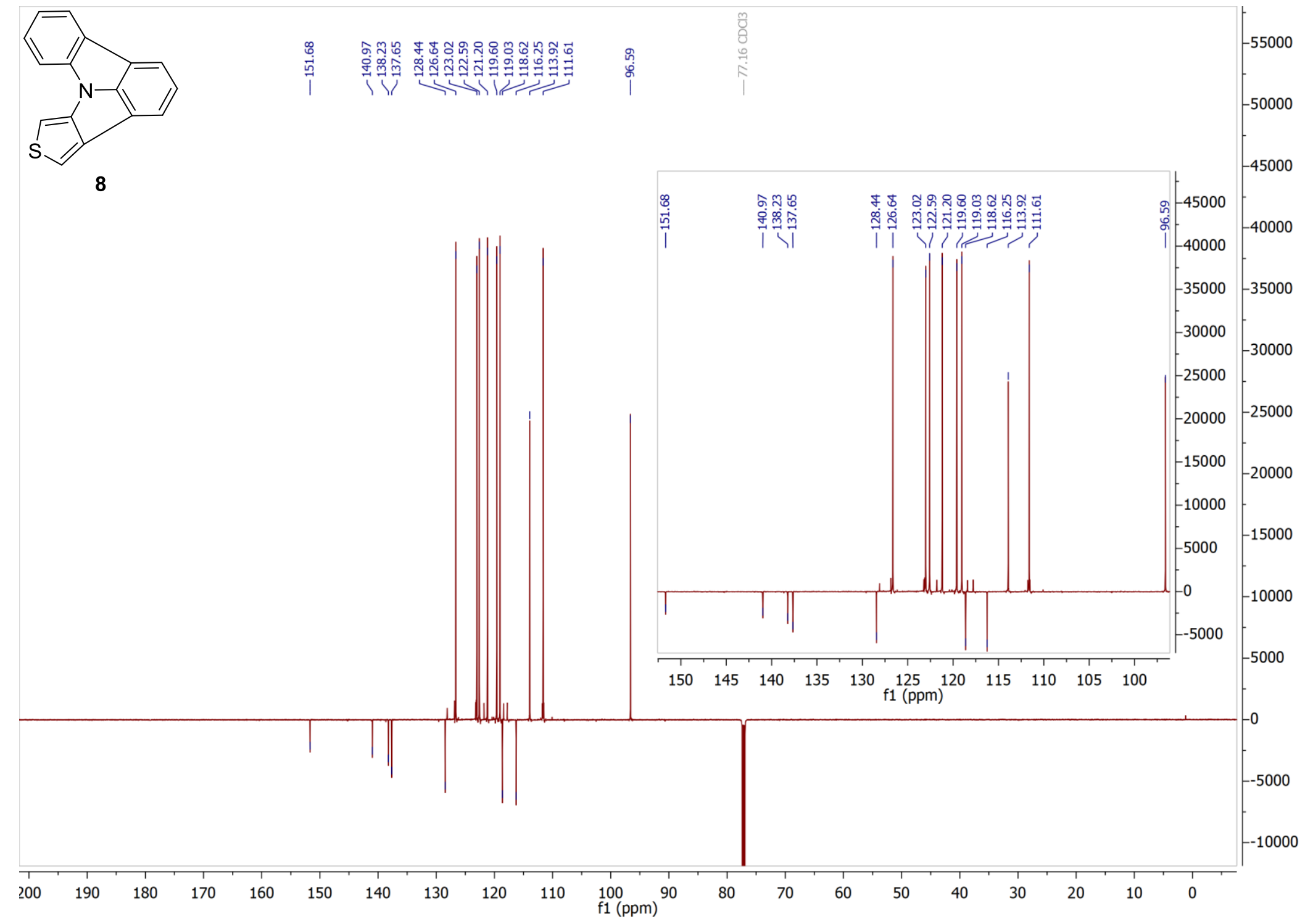

Figure S 12: ${ }^{13} \mathrm{C}$ NMR spectrum of 8 


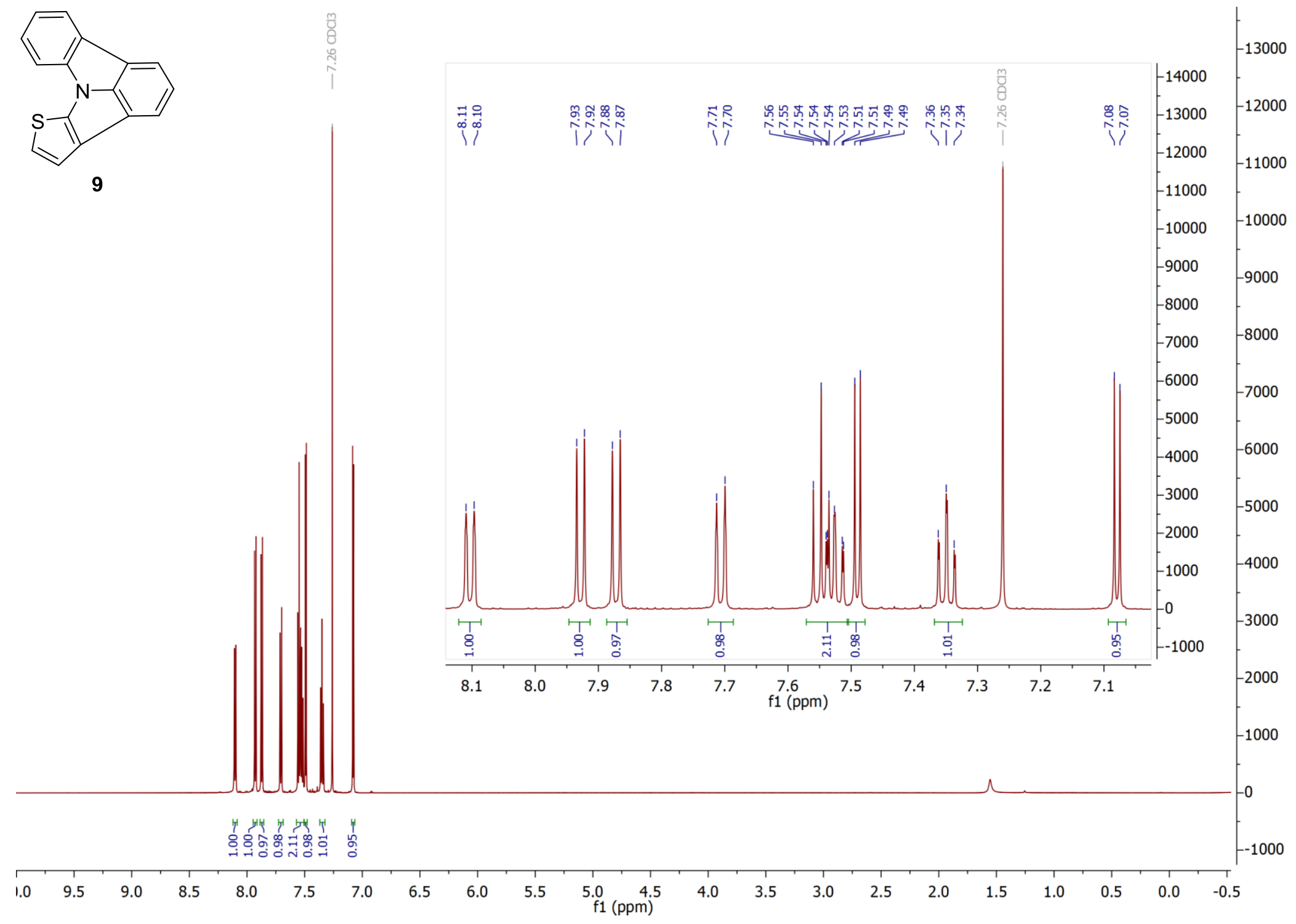

Figure S 13: ${ }^{1} \mathrm{H}$ NMR spectrum of 9 


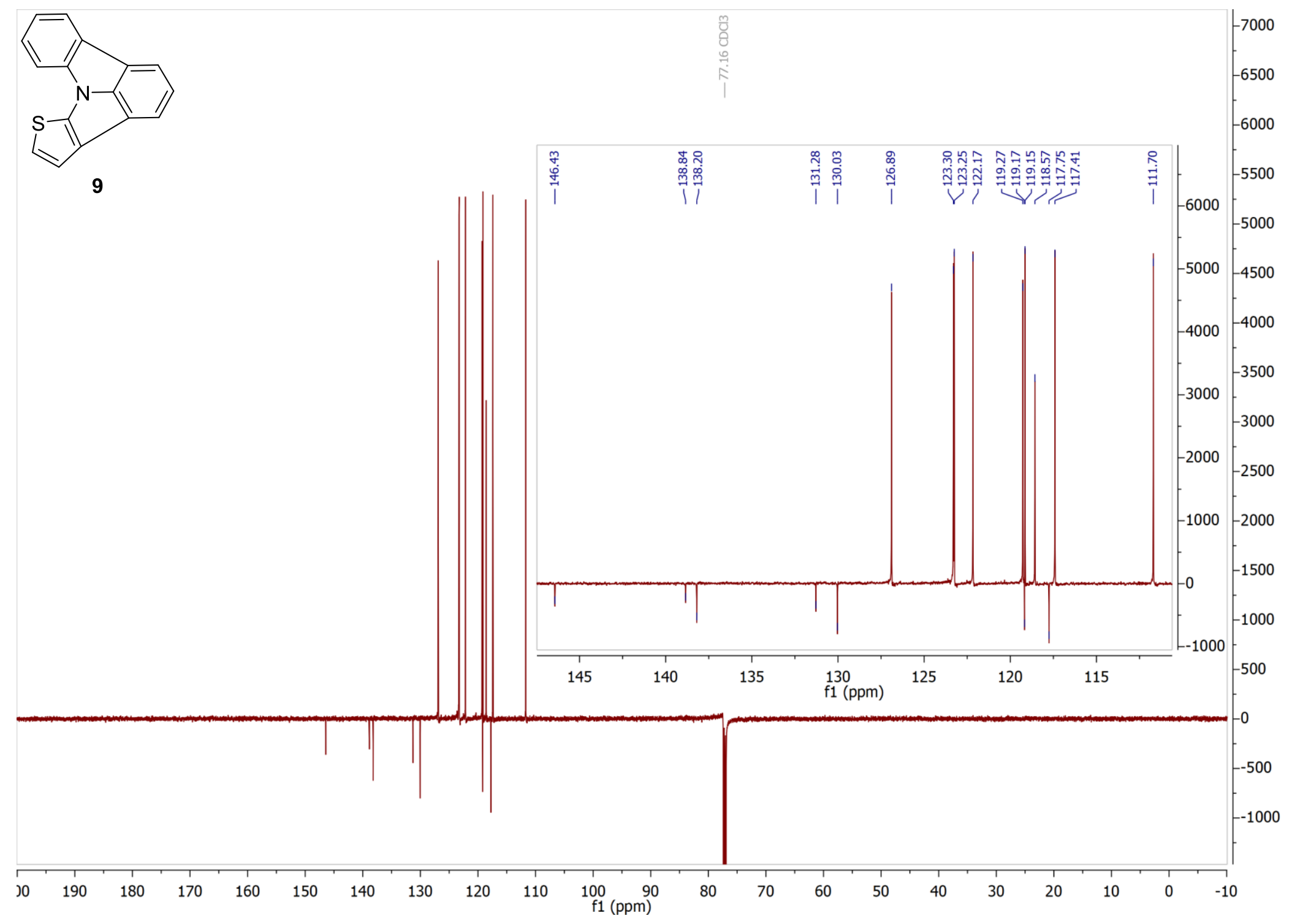

Figure S 14: ${ }^{13} \mathrm{C}$ NMR spectrum of 9 


\section{Cyclic Voltammetry}

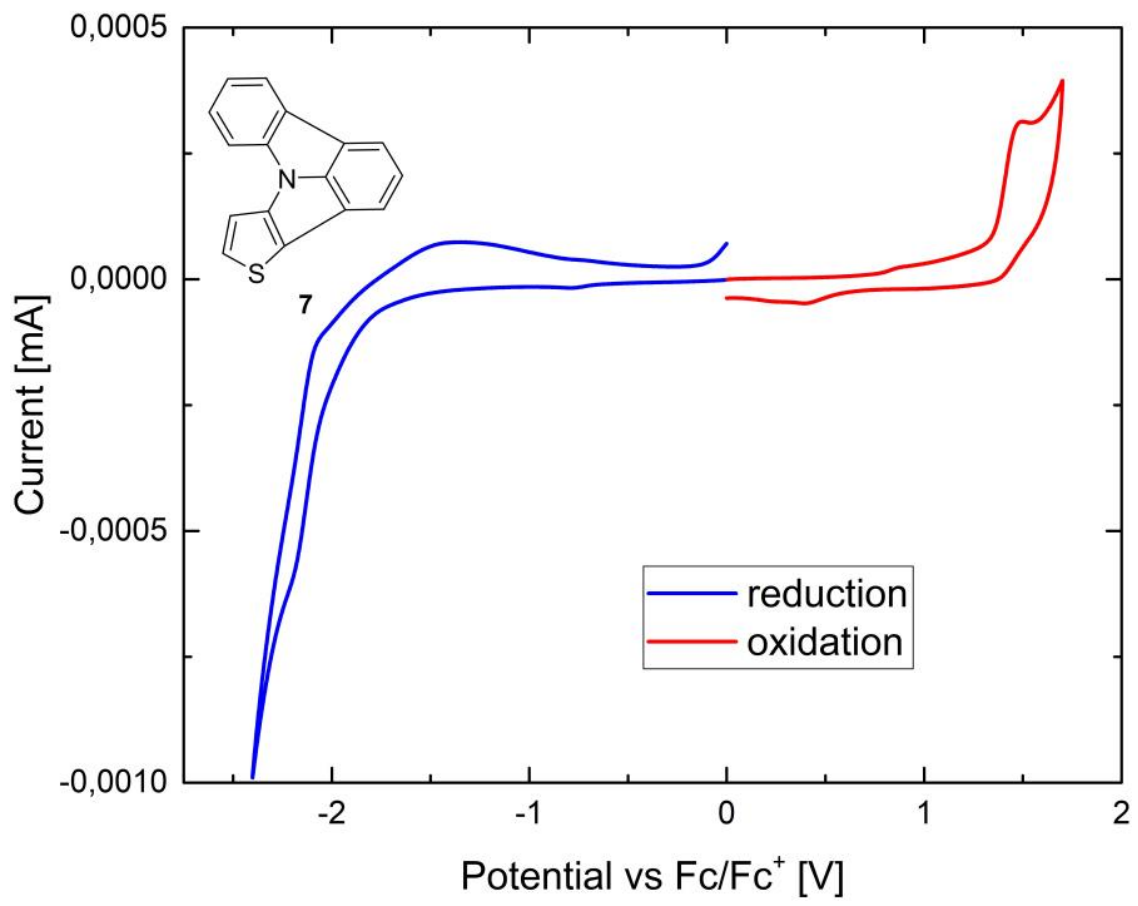

Figure S 15: Cyclovoltamogram of 7

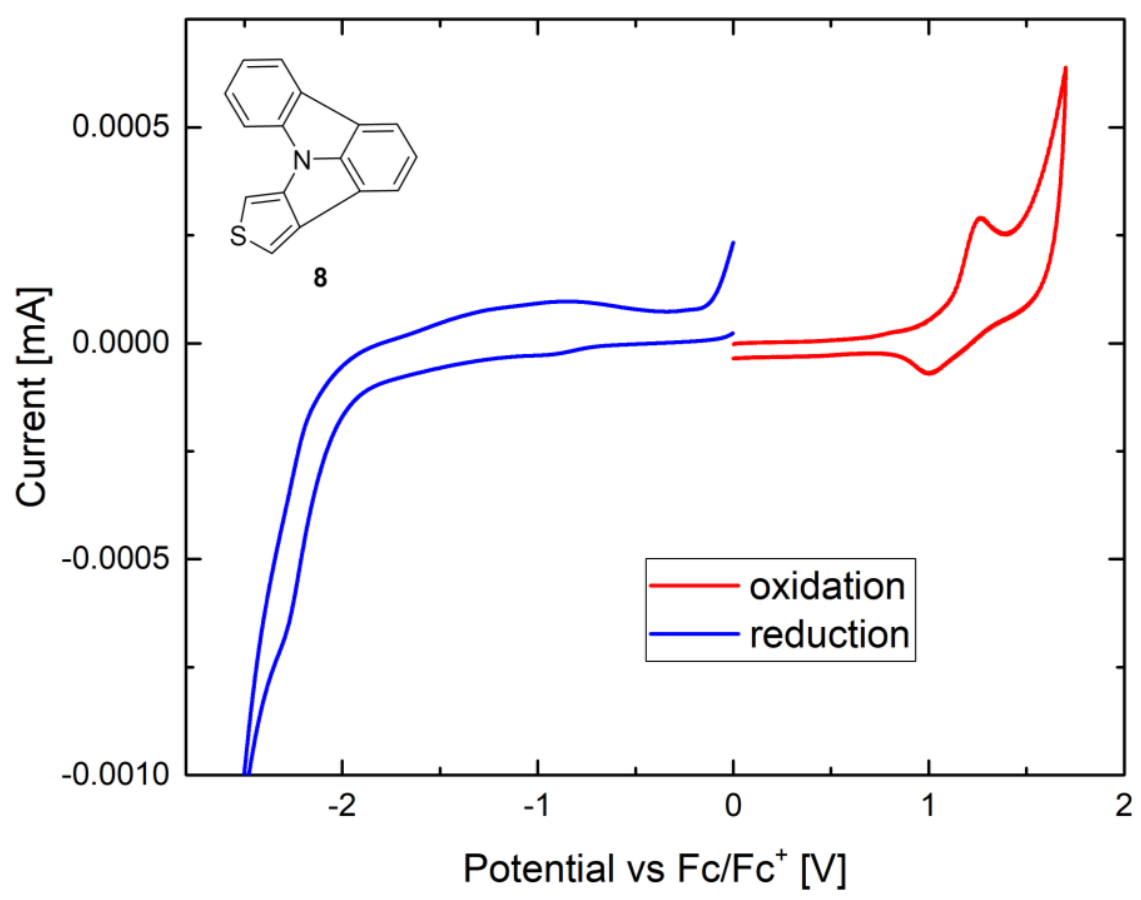

Figure S 16: Cyclovoltamogram of 8 


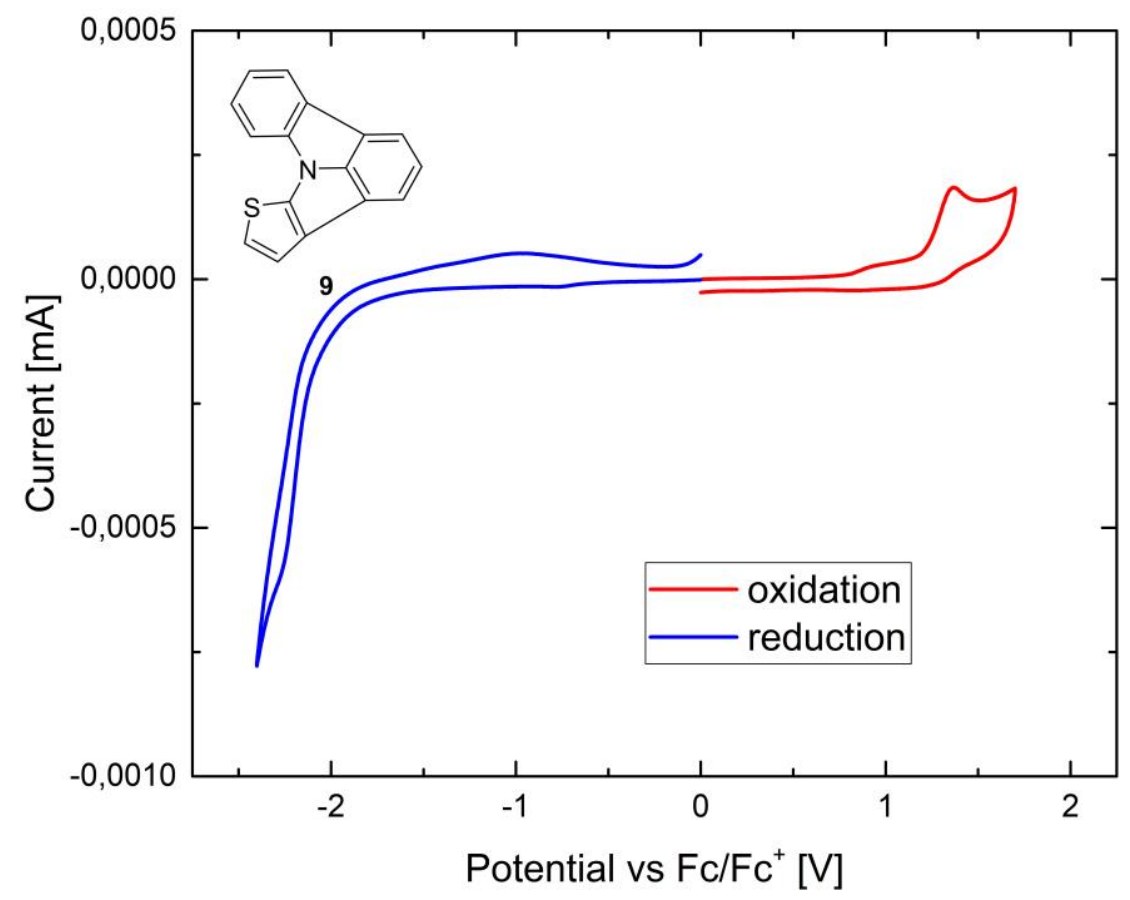

Figure S 17: Cyclovoltamogram of 9

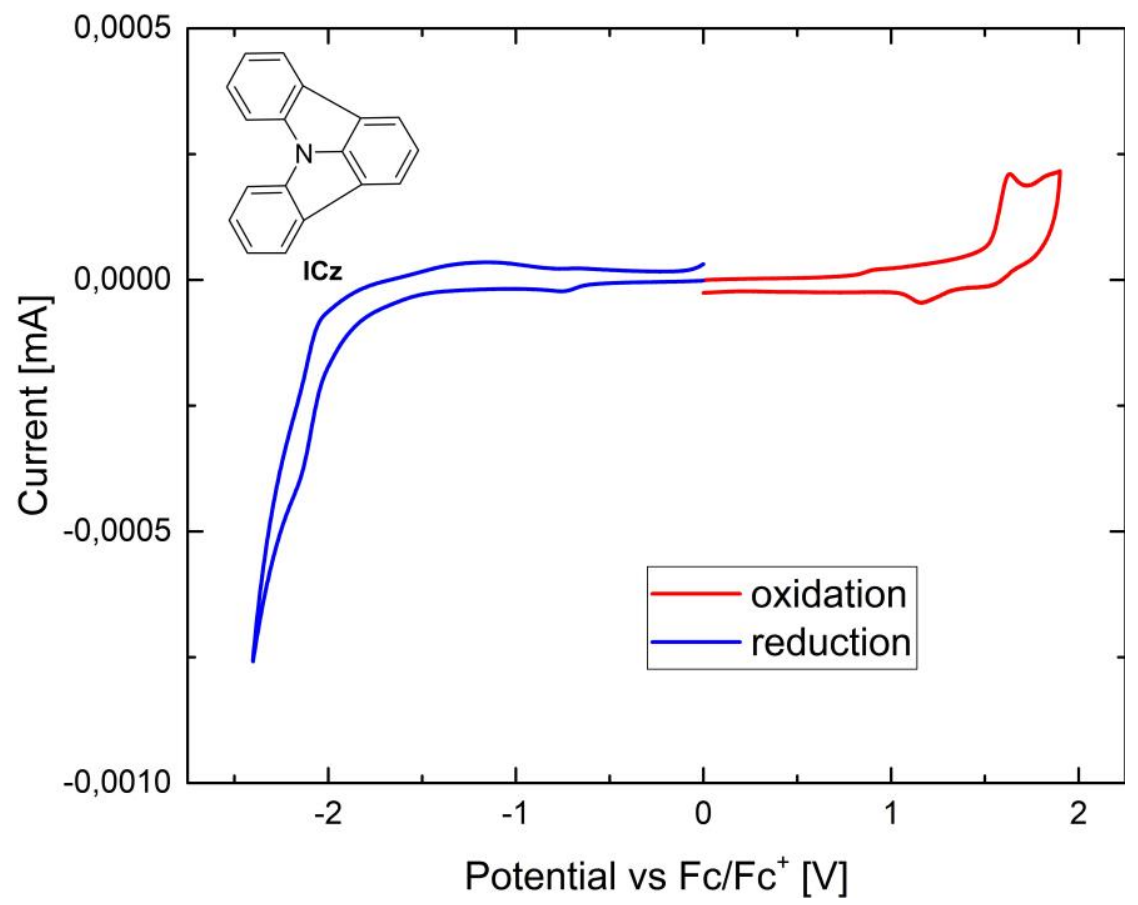

Figure S 18: Cyclovoltamogram of ICZ 


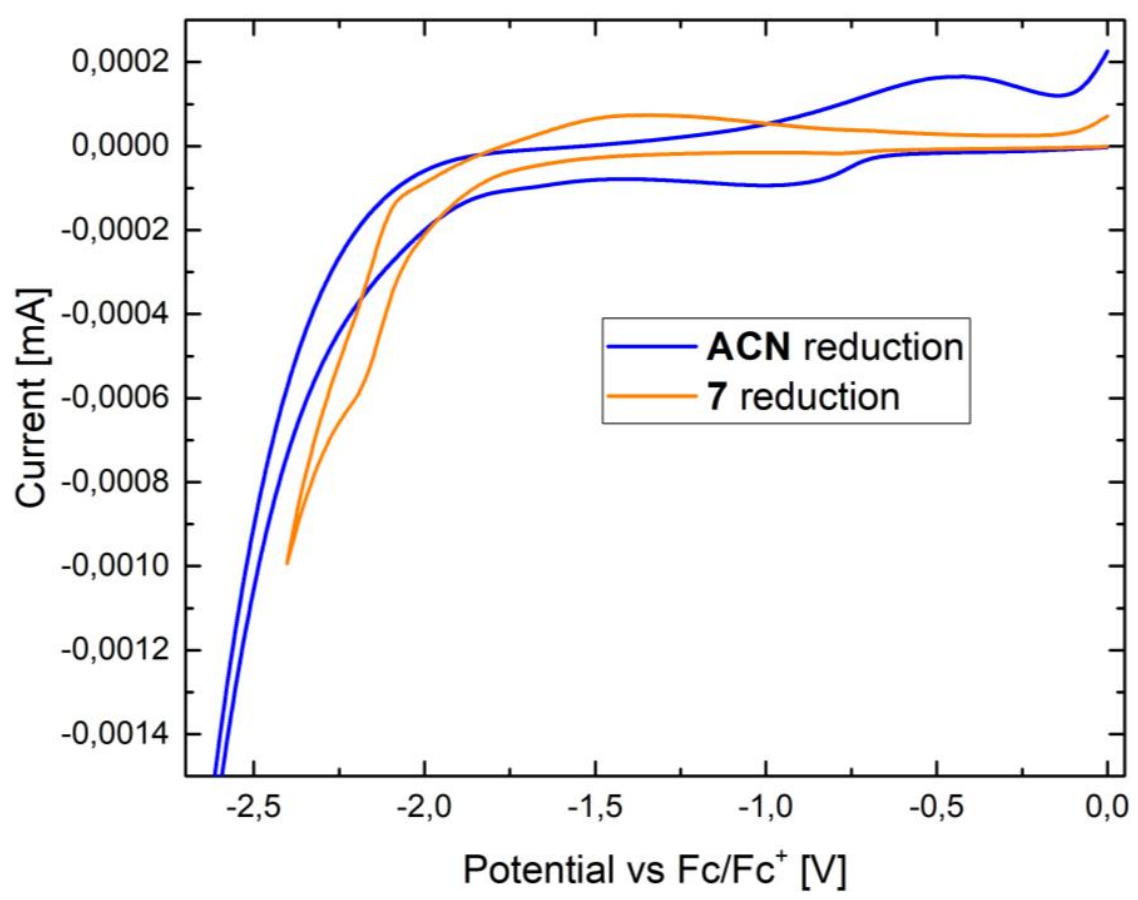

Figure S 19: Cyclovoltamogram of ACN reduction compared to 7

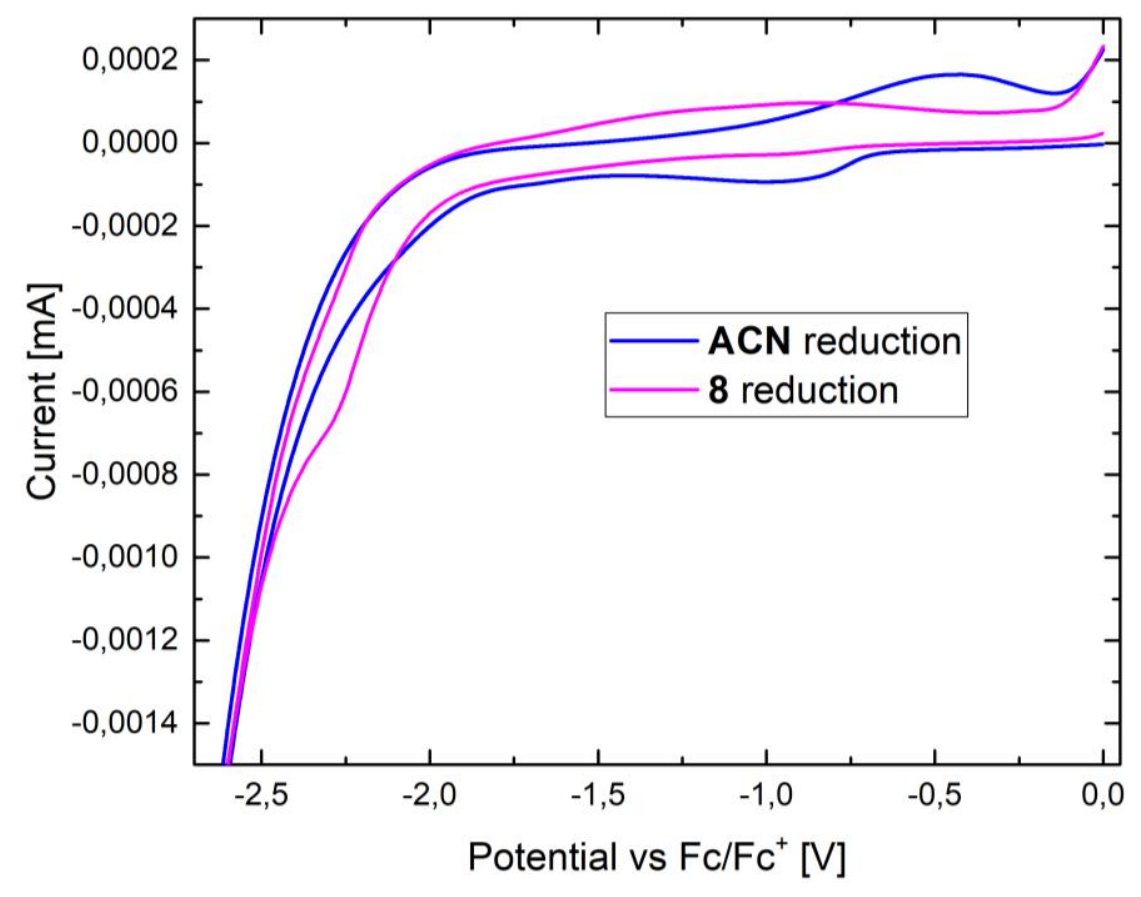

Figure S 20: Cyclovoltamogram of ACN reduction compared to 8 


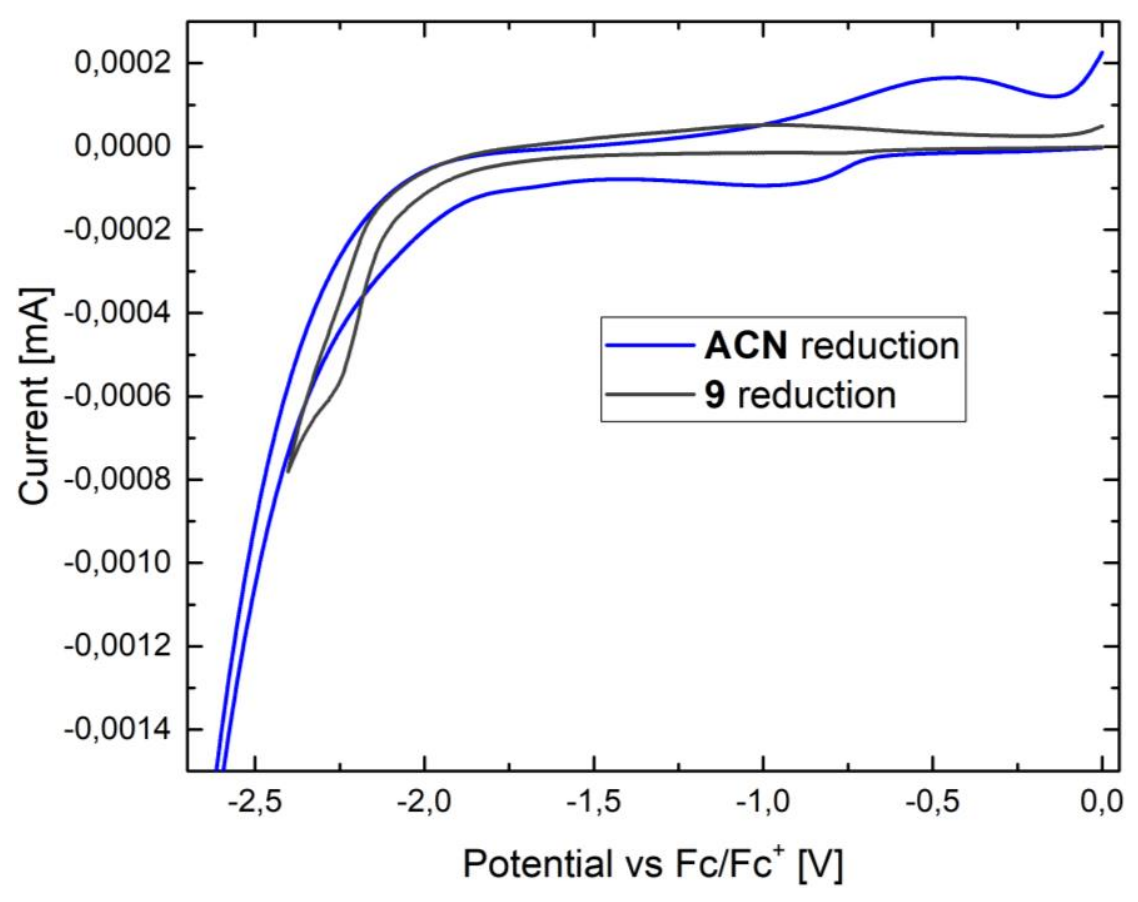

Figure S 21: Cyclovoltamogram of ACN reduction compared to 9

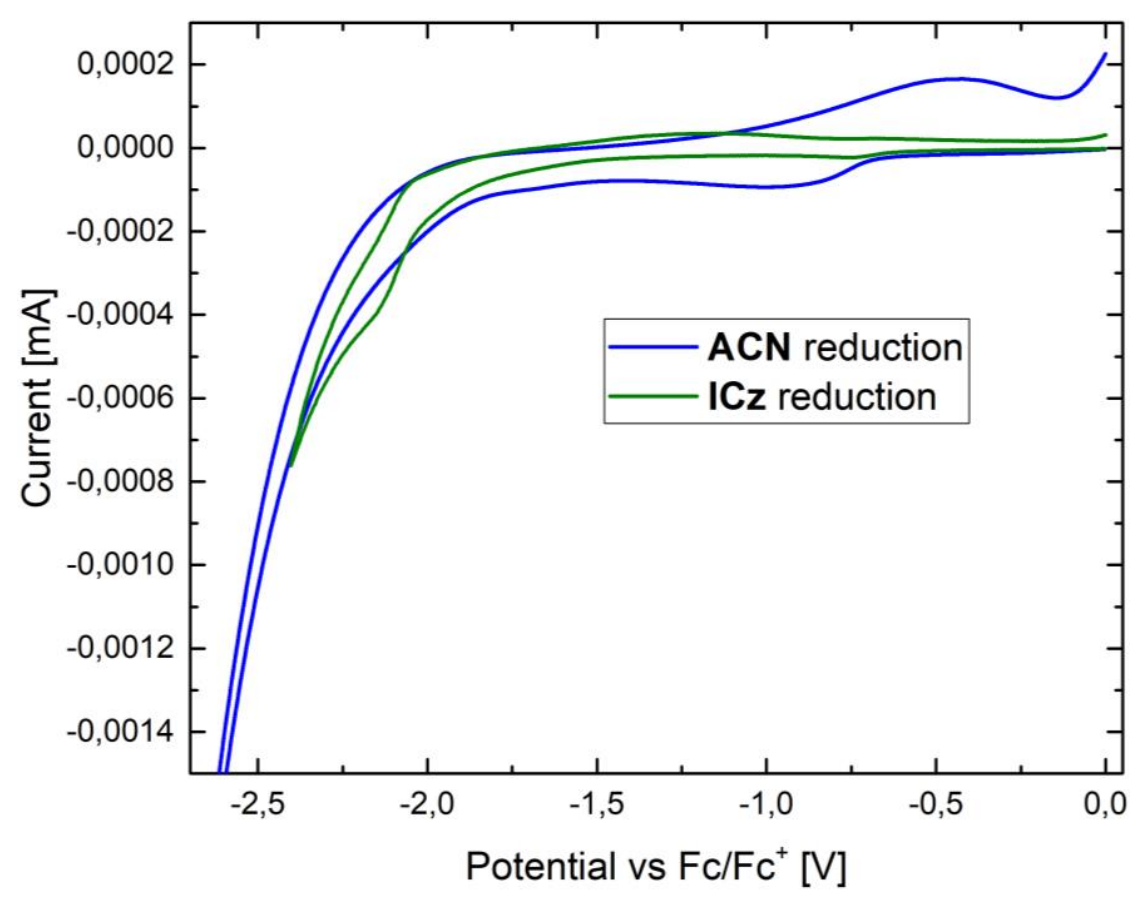

Figure S 22: Cyclovoltamogram of ACN reduction compared to ICz 


\section{HRMS - Spectra}

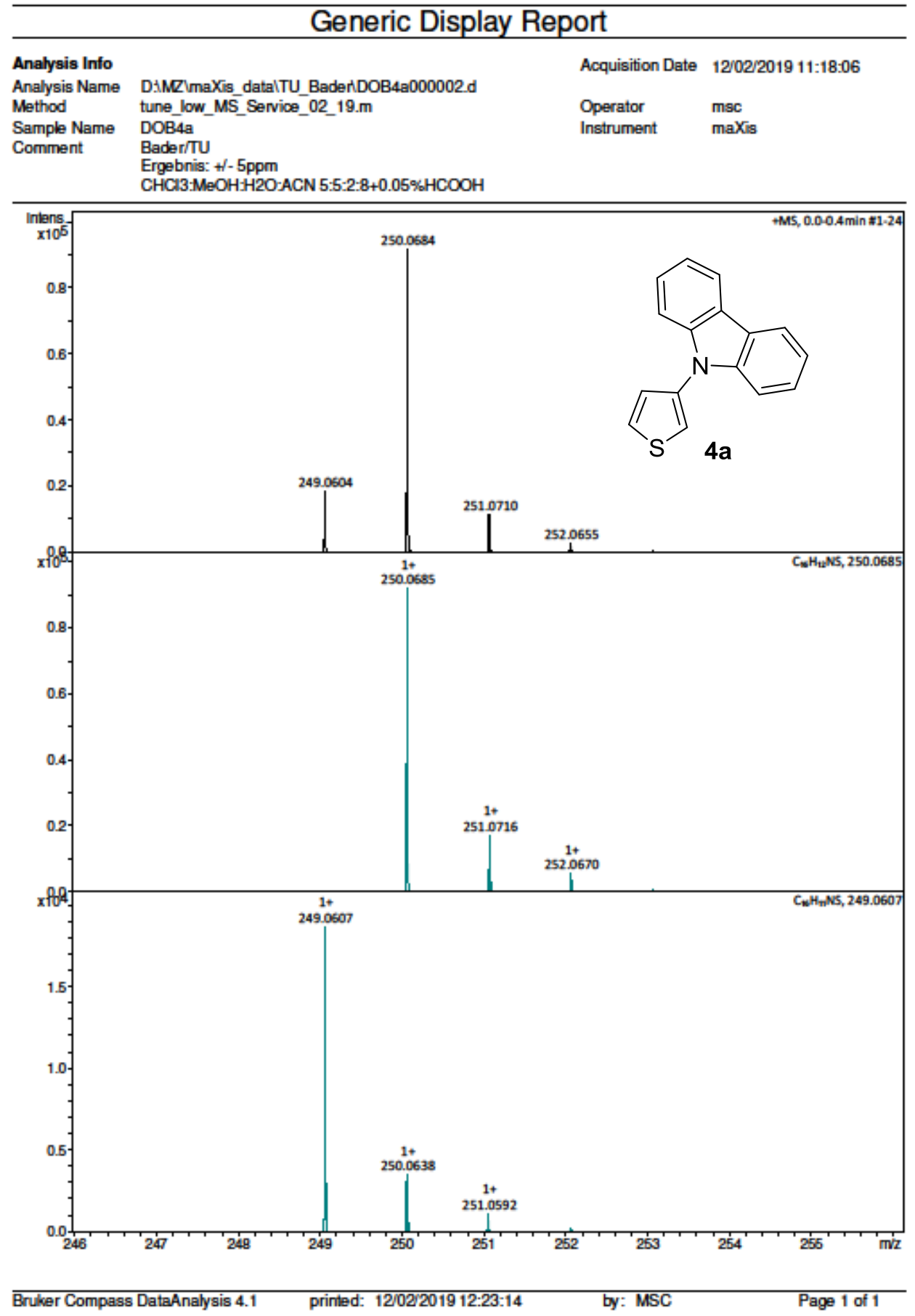

Figure S 23: HRMS spectrum of 4 a 


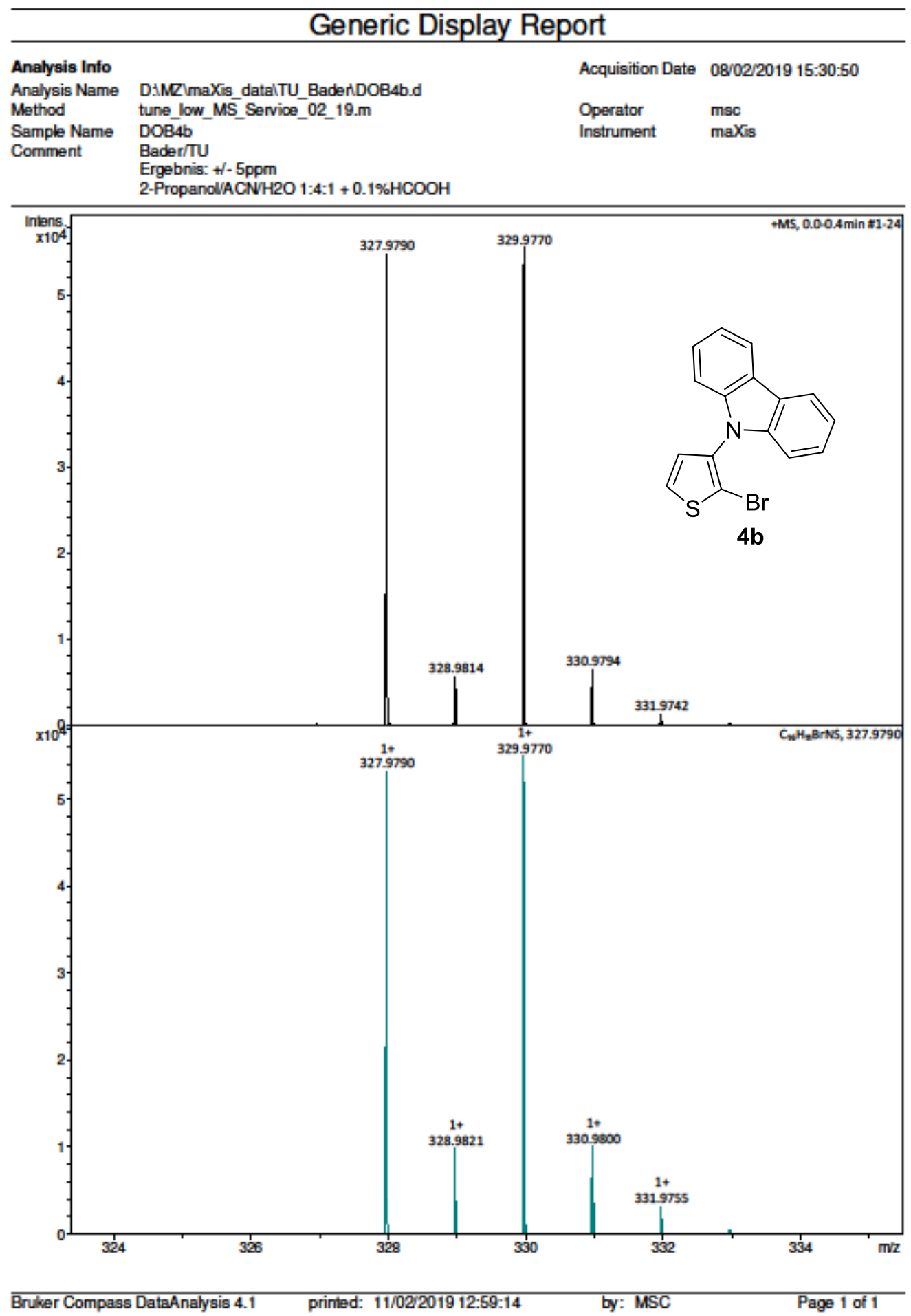

Figure S 24: HRMS spectrum of $\mathbf{4 b}$ 


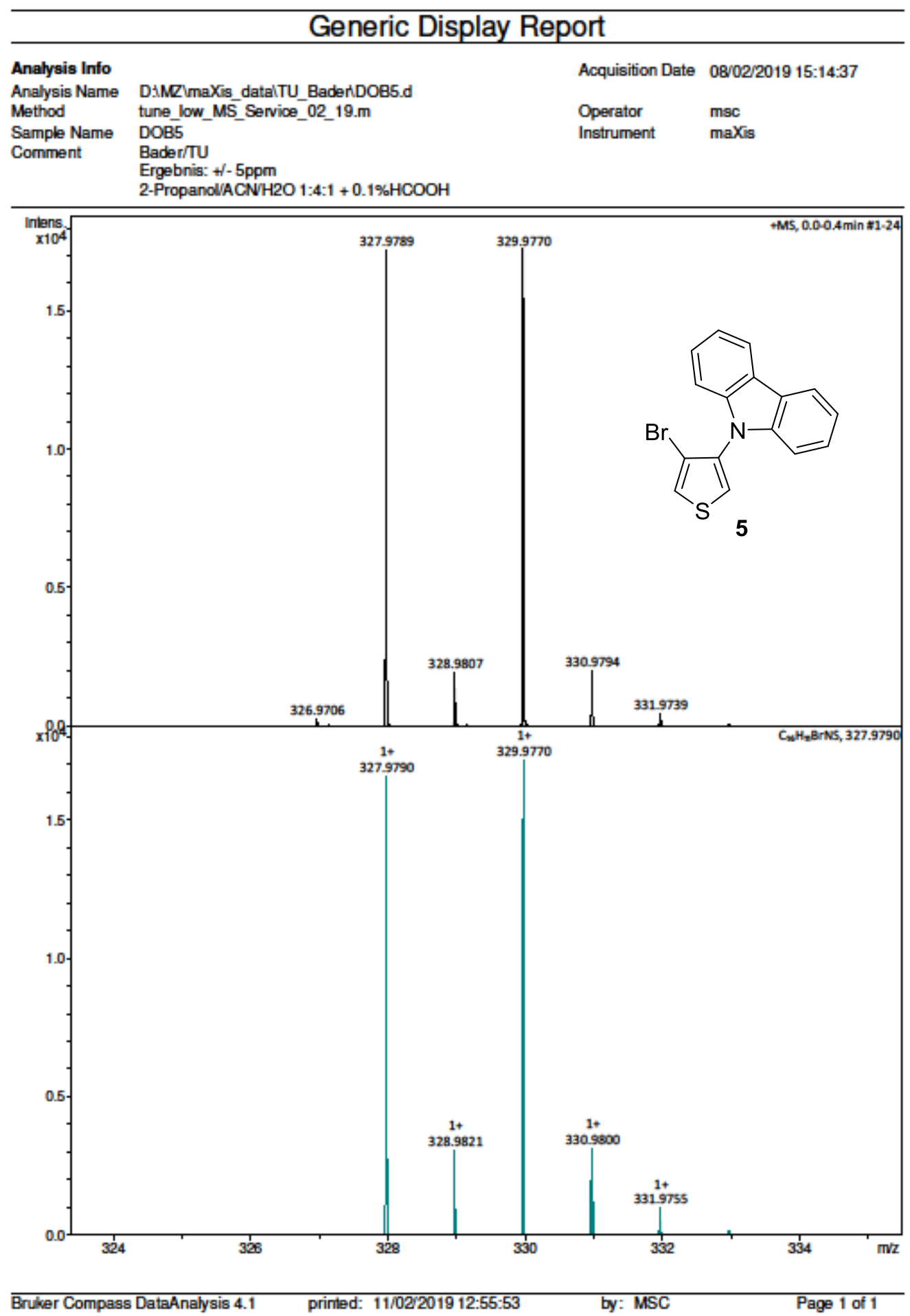

Figure S 25: HRMS spectrum of 5 


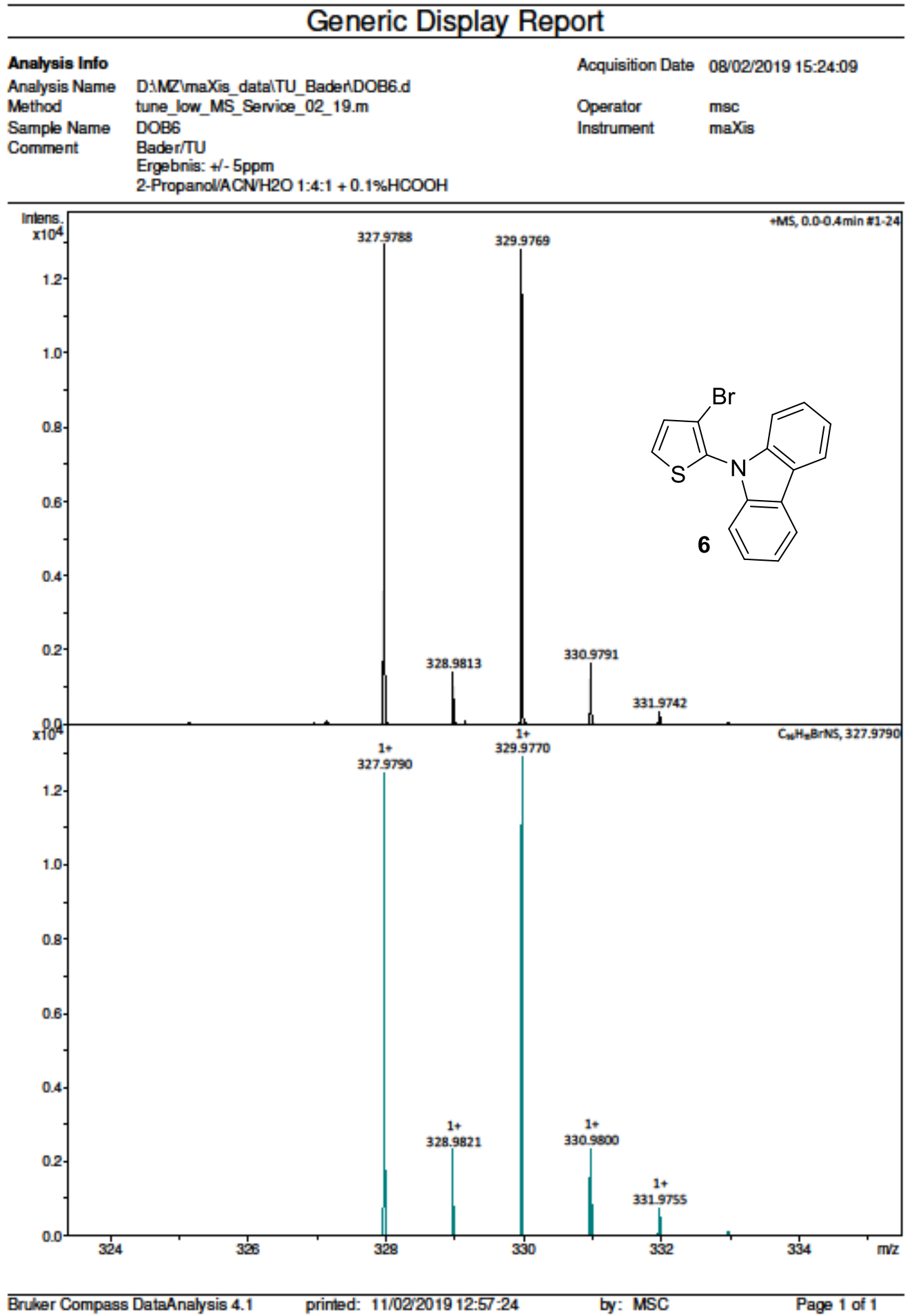

Figure S 26: HRMS spectrum of 6 


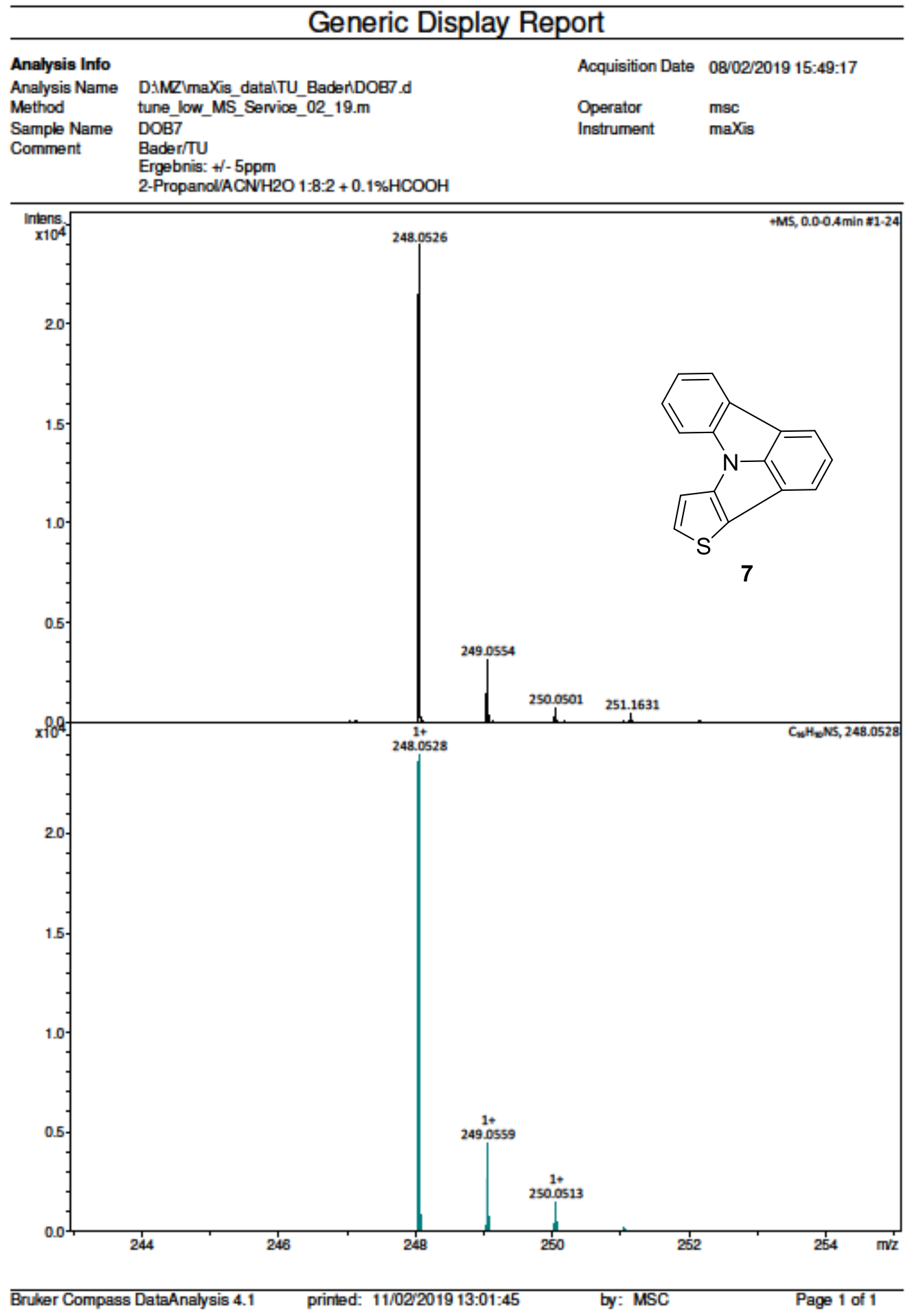

Figure S 27: HRMS spectrum of 7 


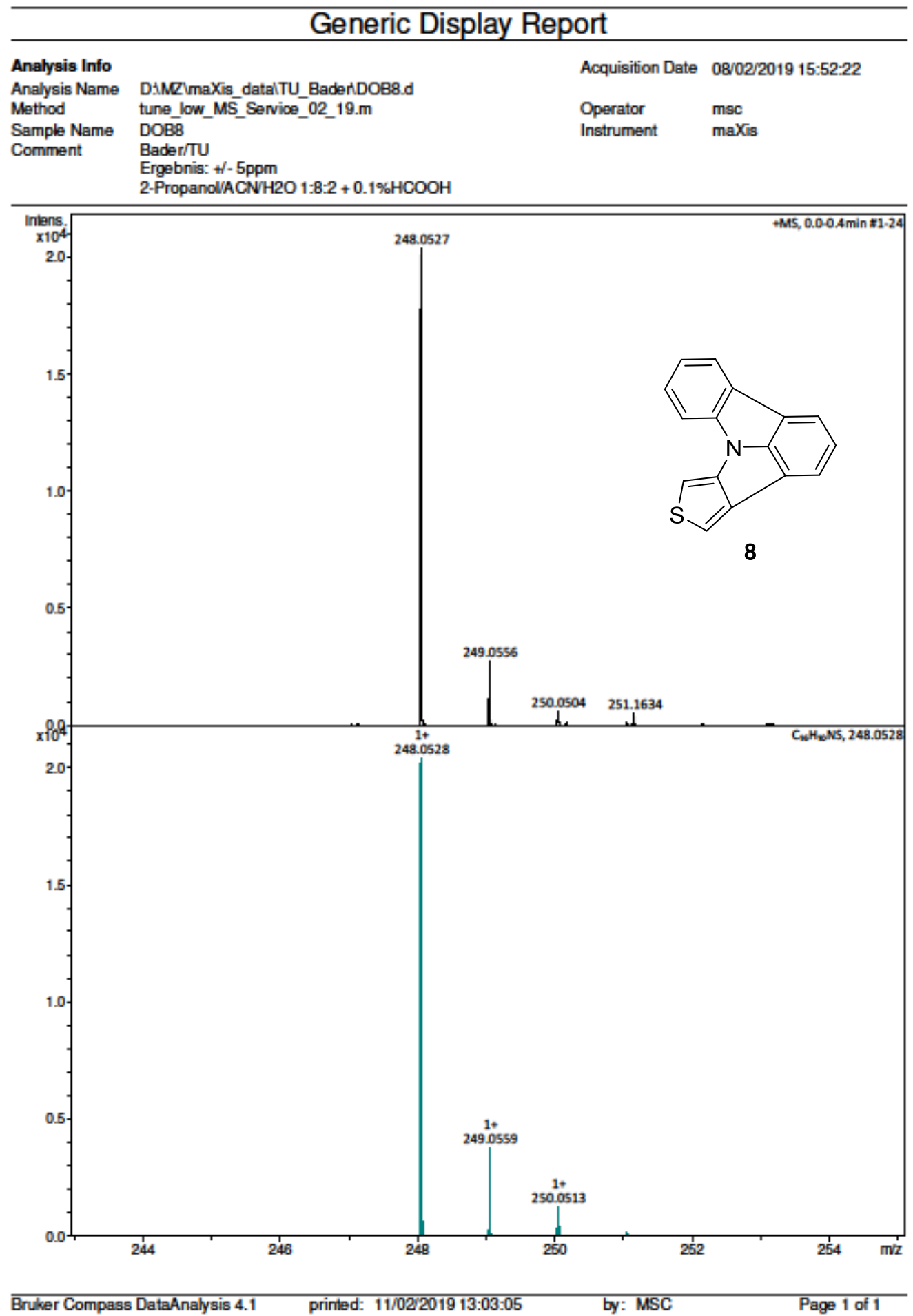

Figure S 28: HRMS spectrum of 8 


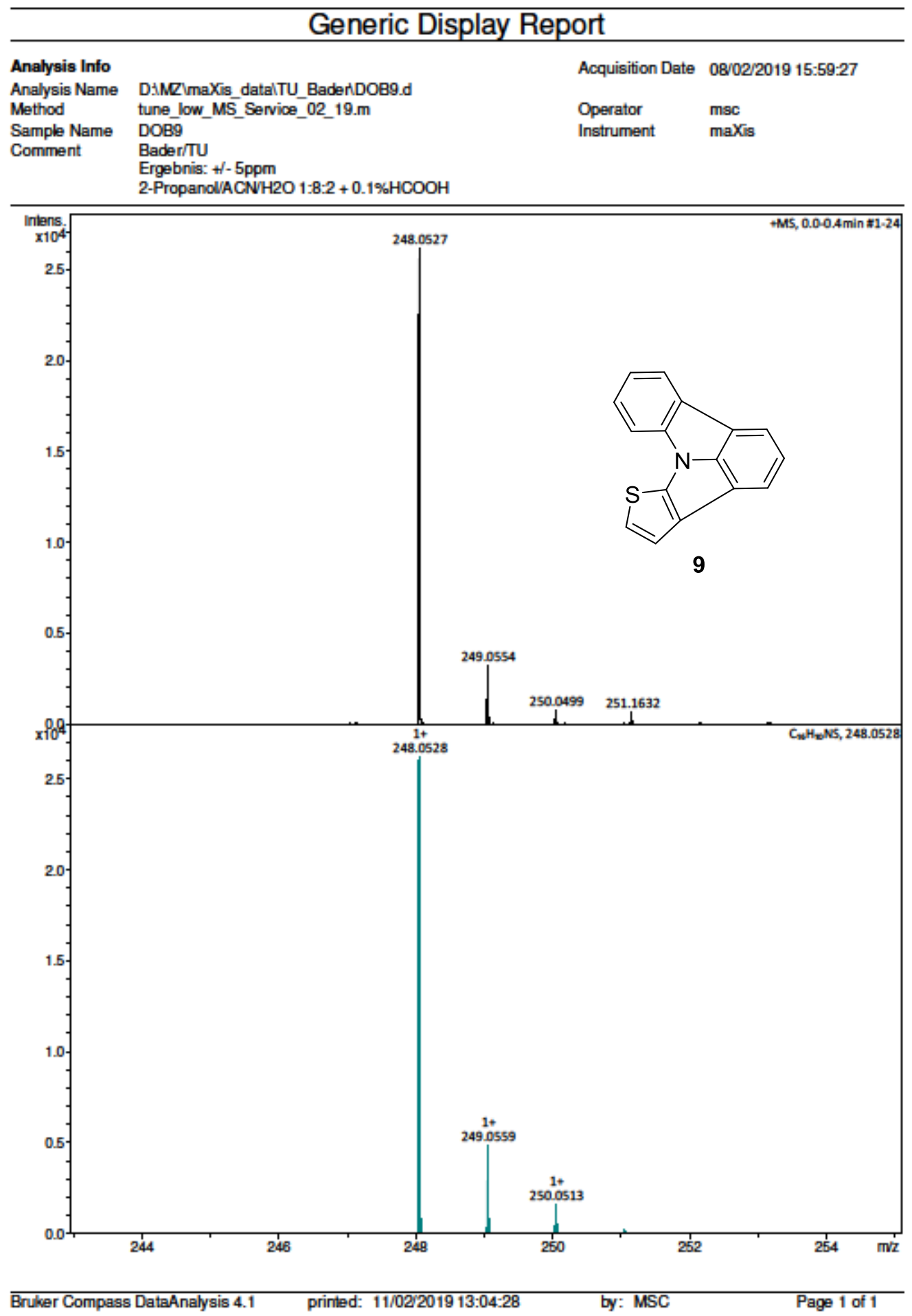

Figure S 29: HRMS spectrum of 9 


\section{Electrochemical and photophysical data}

Table S1. Electrochemical and photophysical data of $\mathrm{ICz}$ and the developed thienopyrrolo[3,2,1-jk]carbazoles 7-9.

\begin{tabular}{cccccccccc}
\hline & $\begin{array}{c}\text { opt. } \mathrm{BG}^{\mathrm{a}, \mathrm{b}} \\
{[\mathrm{eV}]}\end{array}$ & $\begin{array}{c}\lambda_{\max }^{\mathrm{b}, \mathrm{c}} \\
{[\mathrm{nm}]}\end{array}$ & $\begin{array}{c}E_{T}{ }^{\mathrm{d}} \\
{[\mathrm{eV}]}\end{array}$ & $\begin{array}{c}\mathrm{HOMO}^{\mathrm{e}} \\
{[\mathrm{eV}]}\end{array}$ & $\begin{array}{c}\mathrm{LUMO}^{\mathrm{e}} \\
{[\mathrm{eV}]}\end{array}$ & $\begin{array}{c}\lambda_{\max }^{\mathrm{b}, \mathrm{f}} \\
{[\mathrm{nm}]}\end{array}$ & $\begin{array}{c}\varepsilon_{\text {max }}^{\mathrm{f}, \mathrm{h}} \\
{\left[\mathrm{L}^{*} \mathrm{~mol}^{-1} \mathrm{~cm}^{-1}\right]}\end{array}$ & $\begin{array}{c}\lambda_{\text {low }}^{\mathrm{b}, \mathrm{g}} \\
{[\mathrm{nm}]}\end{array}$ & $\begin{array}{c}\varepsilon_{\text {low }}^{\mathrm{g}, \mathrm{h}} \\
{\left[\mathrm{L}^{*} \mathrm{~mol}^{-1} * \mathrm{~cm}^{-1}\right]}\end{array}$ \\
\hline $\mathrm{ICz}$ & 3.30 & 375 & 2.84 & -5.78 & -2.27 & 285 & 37720 & 363 & 11100 \\
7 & 3.25 & 390 & 2.57 & -5.68 & -2.38 & 280 & 29500 & 347 & 15140 \\
8 & 3.30 & 380 & 2.71 & -5.56 & -2.28 & 284 & 27760 & 369 & 5880 \\
9 & 3.22 & 410 & 2.79 & -5.53 & -2.30 & 283 & 42900 & 345 & 4720
\end{tabular}

${ }^{\mathrm{a}} \mathrm{HOMO}-\mathrm{LUMO}$ energy gaps, determined from the absorption onset. ${ }^{\mathrm{b}}$ measured in DCM solutions $(5 \mu \mathrm{M})$ at room temperature; ${ }^{c}$ emission maximum; determined from the highest vibronic transition in solid solutions of toluene/iPrOH $(10: 1 ; 1 \mathrm{mg} / \mathrm{ml})$ at $77 \mathrm{~K} ;{ }^{\mathrm{e}}$ calculated from the onset of the oxidation and reduction peak observed during cyclic voltammetry relative to ferrocene/ferrocene ${ }^{+}(4.8 \mathrm{eV})$; $^{\mathrm{f}}$ absorption maximum (only peaks $>270 \mathrm{~nm}$ considered due to possible solvent interference); ${ }^{\mathrm{g}}$ lowest energy absorption peak; ${ }^{\mathrm{h}}$ molar attenuation coefficient, calculated from absorption. 